\title{
단기간 정적·동적 허리 안정화 운동이 만성 허리통증 20대 여대생의 체간 근력 및 근지구력에 미치는 영향
}

\section{두영택 ${ }^{1)}$. 엄우섭 $2^{2 *}$}

1) 광주여자대학교 2) 서울교육대학교

\begin{abstract}
Young-Taek Doo - Woo-Seob Eom. Effect of Short Term Static Dynamic Lumbar Stability Exercise on the Trunk Muscles Strength and Endurance of Chronic Low Back Pain Female College Students in Their 20's. KINESIOLOGY, 2016, 18(2): 63-69. [PURPOSE] The purpose of this study was to evaluate effects of short term static - dynamic lumbar stability exercise on the trunk muscles strength and endurance of chronic low back pain female college students in their 20's. [METHODS] The subjects were consisted of twenty patients who had non specific chronic low back pain. All subjects randomly assigned to the static lumbar stabilizing exercise group $(\mathrm{n}=10)$ and dynamic lumbar stabilizing exercise group. Dynamic lumbar stabilizing exercise group received 3D balance, static lumbar stabilizing exercise group received bridge exercise during 4 weeks period. HUR was used to measure the isometric muscle strength. Time watch measure method was used to measure the abdominal and back muscle strength and endurance of trunk flexion and extension. [RESULTS] The trunk muscle strength was significantly difference between group $(p<05)$, Short term dynamic lumbar stabilizing exercise group was significantly increased than short term static lumbar stabilizing exercise group $(p<.05)$. Endurance of trunk flexion, extension weren't significantly difference between group $(p>$.05). [CONCLUSIONS] Short term dynamic lumbar stabilizing exercise group showed increase in trunk muscle strength. Both group were increased endurance of trunk flexion, extension. Therefore, Short term dynamic and static lumbar stabilizing exercise will be available in the intervention of chronic low back pain patients.
\end{abstract}

Key words : short term static and dynamic lumbar stability exercise, trunk muscle strength and endurance, chronic low back pain 주요어 : 단기간 정적·동적 허리 안정화 운동, 체간 근력 및 근지구력, 만성 허리 통증

\section{서론}

현대 사회에서 신체활동 부족 및 영양과잉 등의 부 정적인 생활습관과 업무상 컴퓨터 활용 및 공부시간 의 증가로 인한 자세의 불균형과 국부관절의 과사용 에 의한 근골격계 손상 등의 질환이 증가하고 있다. 특히, 대학생들의 경우 $80 \%$ 정도가 허리통증을 경험 하게 되고, 이들 중 $15 \%$ 는 만성 허리통증질환자로 발 전하는 것으로 나타났다(Wang \& Wang, 2009). 최근, 장시간 지속되는 좌업생활로 인하여 복근을 중심으로 한 근력의 저하가 누적되어 한쪽으로 치우치는 체형 불균형이 빈번히 발생하고 있다. 장시간 앉아서 공부 하는 시간의 증가, 신체의 활동량 부족, 바르지 못한 자세유지 및 신체 불균형에 대한 자각도 부족 등의
이유로 발생하는 만성 허리 통증은 심각한 건강 문제 로 대두되고 있다(Lee et al., 2011).

산업이 발달하고 문명의 이기를 이용한 문화생활로 좌업생활이 증대되었고, 교통수단의 발달로 인한 보행 기회의 감소는 다리 근력 및 근지구력의 약화를 초래 하였으며, Park(2002)은 체간의 근육이 허리의 기능을 수행할 수 없을 정도로 약화되면 반복적인 작은 손상 에도 더 예민하게 되어 허리 손상을 입게 되고, 만성 적인 허리통증을 유발하여 업무와 일상생활에 지장을 초래한다고 하였다.

허리 안정화의 목적은 약화된 근력 근지구력의 강 화, 비대칭적인 근력 및 근지구력 불균형에 대한 교 정, 짧아진 근육, 건, 그리고 인대의 신장, 증가된 척 추 전만증의 경감 및 경직된 허리의 유연성 등을 증

* 교신저자: ews@snue.ac.kr 
가시키는데 있다. 특히, 허리통증 환자의 기능 회복과 통증감소를 위한 대표적인 운동으로 정적 및 동적 허 리 안정화 운동이 사용되고 있다(Kim, 1999).

정적 허리 안정화 운동과 분절 안정화 운동 모두 뭇 갈래근 단면적을 증가시켰다고 보고하였고(Kim et al., 2008), 허리 근육에 초점을 둔 근력 및 유연성 운동이 허리 근력을 향상시켰다고 보고하였다(Kim et al., 1999).

동적 허리 안정화 운동은 동적 균형을 증가시켜 척 추의 안정성을 증가시켜 손상을 예방하는 효과가 있 으며, 지면과 같은 정적인 환경보다 동적인 환경에서 안정화 운동을 수행하는 것이 고유수용기를 자극하여 대뇌의 운동기관에 자극을 주게 되어 균형감각과 균 형유지 능력을 극대화(Stevens et al., 2006), 척추 안 정화 및 근력 강화와 허리 통증이 감소(Shin et al., 2012), 그리고 일반적인 척추강화운동보다 통증 감소, 기능개선, 척추 주변 근력증가 및 뭇갈래근의 근단면 적 증가에도 효과적이라고 하였다(Kwon et al., 2006).

이에, 본 연구에서는 20대 여대생을 대상으로 단기 간 정적 및 동적 허리 안정화 운동프로그램을 적용하 여 20대 여대생에게 근력강화에 어떤 운동형태가 더 효과적인지를 알아봄으로써 일반인들이 일상생활에서 허리 안정화를 위하여 단기간에 좀 더 효과성을 높일 수 있는 운동프로그램의 기초자료를 제공하는데 있다.

\section{연구방법}

\section{연구대상}

본 연구는 2014년 4 월 28 일 부터 5월 30일까지 광주 $\mathrm{K}$ 대학교에 재학 중인 20대 여대생 20명을 선정하여 정적 허리 안정화 운동 그룹에 10 명, 동적 허리 안정화 운동 그룹에 10 명씩을 무작위 배치하였다. 연구대상자 모두에게 실험동의서를 받은 후 실험을 진행하였다. 연 구대상자 선정기준은 허리통증이 VAS 3이상, 6개월 이 상 지속된 자, 그리고 일주일 동안 3번 이상 운동할 수 있는 자로 하였고, 제외기준은 본 연구에서 적용하는 안정화 운동에 부정적 영향을 미칠 수 있는 사람으로 최근 1 년 동안 허리수술을 받은 자, 신경계 장애가 있
는 자, 허리에 관련된 약물을 복용하는 자로 하였다. 연구대상자의 신체적 특성은 <Table 1>과 같다.

Table 1. Characteristics of Subjects

$(\mathrm{M} \pm \mathrm{SD})$

\begin{tabular}{ccccc}
\hline Group & $\mathrm{n}$ & Age $(\mathrm{yrs})$ & Height $(\mathrm{cm})$ & 체중 $(\mathrm{kg})$ \\
\hline \hline $\begin{array}{c}\text { Static stability } \\
\text { exercise }\end{array}$ & 10 & $21.4 \pm 1.17$ & $162.7 \pm 4.00$ & $52 \pm 5.17$ \\
$\begin{array}{c}\text { Dynamic } \\
\text { stability exercise }\end{array}$ & 10 & $20.5 \pm 0.85$ & $163.6 \pm 3.40$ & $56.2 \pm 7.20$ \\
\hline
\end{tabular}

\section{측정항목 및 방법}

체간 근력

체간 근력 측정은 $\mathrm{HUR}$ (수동식 정형용 운동장치, $\mathrm{AB} \mathrm{HUR} \mathrm{Oy,} \mathrm{핀란드)을} \mathrm{이용하여} \mathrm{복부근과} \mathrm{배부근의}$ 등척성 근력을 각각 측정하였다. 3 회 측정하여 평균값 을 사용하였으며, 근피로가 측정값에 영향을 미치지 않도록 1 회 실시 후, 1 분간의 휴식시간을 가졌다. 단 위는 Nm로 기록하였다(Shin, 2012).

\section{복부근 근력}

앉은 자세에서 팔을 $X$ 자 모양으로 가슴과 복부 사이 에 위치하고, 바닥에 발을 고정시킨 상태에서 복부근을 이용하여 최대로 체간 굴곡 시 측정하였다<Figure 1>.

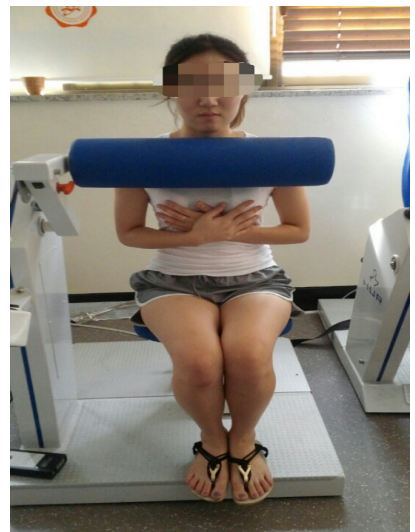

Figure 1. A measuring posture of abdominal muscle strength

\section{배부근 근력}

배부근 근력은 연구대상자가 복부근 근력 측정 자 세의 반대로 앉은 상태에서 복부근 근력 측정방법과 
동일한 자세를 취한 뒤, 배부근을 이용하여 등을 최대 한 뒤로 펴도록 하여 측정하였다. 이 때 등의 힘만을 발휘하여 체간을 신전하도록 하였다<Figure 2>.

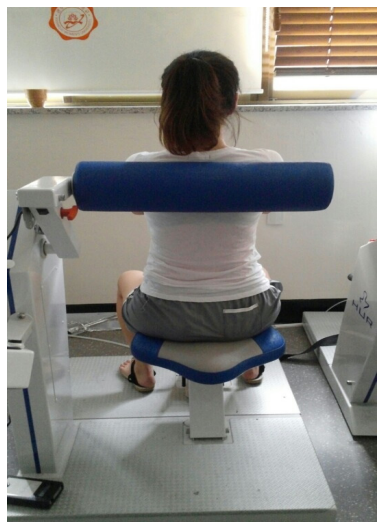

Figure 2. A measuring posture of back muscle strength

\section{체간 근지구력}

체간 근지구력은 복부근과 배부근의 등척성 근지구 력을 각각 측정하였다. 연속적 등척성 근지구력 측정은 피험자에게 일정한 시간동안 최대 힘을 발휘하도록 하 고, 일정 시간 범위 내에서 시간에 따른 힘의 변화를 관찰하는 방법을 적용하여 각 자세를 유지하는 시간을 초 단위로 측정하였다(Deeb et al., 1992). 근피로를 줄 이기 위해 1 회 측정 시마다 1 분간 휴식시간을 가지면 서 3회 측정하였고, 자료는 평균값을 사용하였다.

\section{등척성 복부근 근지구력}

등척성 복부근 근지구력은 몸통 굽힘으로 측정하였 으며, 연구대상자는 바로 누운 자세에서 무릎을 세우 고 손이 무릎에 닿게 어깨를 들어서 유지하는 시간을 초 단위로 측정하였다<Figure 3>.

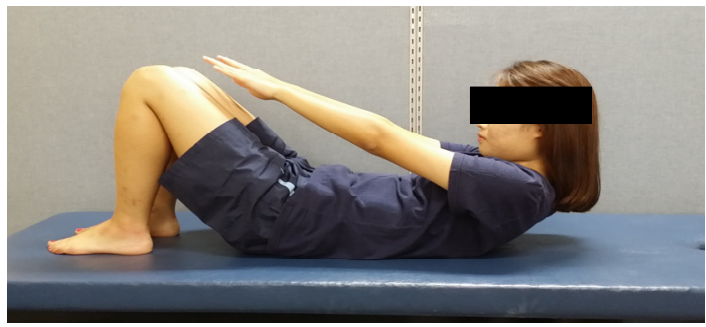

Figure 3. A measuring posture of isometric abdominal muscle endurance

\section{등척성 배부근 근지구력}

등척성 배부근 지구력은 엎드려 상체를 뒤로 젖힌 자세에서 주로 척추기립근과 뭇갈래근의 지구력을 검 사하였다. 보조자는 연구대상자의 발목을 잡아 다리가 들리지 않도록 고정하고 대상자는 엎드려 누운 자세 에서 손을 머리 뒤로 한 상태에서 머리, 가슴, 갈비뼈 가 검사대에서 들어 올려 유지되는 시간을 초단위로 측정하였다(Moreland et al., 1997)<Figure 4>.

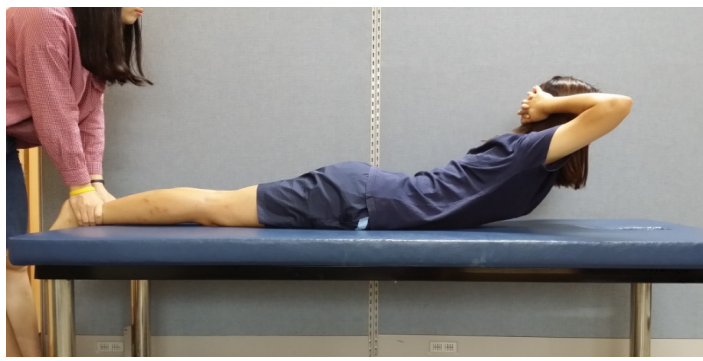

Figure 4. A measuring posture of isometric back muscle endurance

\section{허리 안정화 운동프로그램}

허리 안정화 운동은 주 3 회, 1 회 1 시간씩, 4 주간 실 시하였으며, 본 운동 전에 본 연구에 영향을 미치지 않는 준비운동을 5 분간 실시하였고, 점진적 운동부하 를 위해 1 2주는 3 Sets, 3주는 4 Sets, 4주는 5 Sets 로 각각 실시하였다.

\section{정적 안정화 운동}

정적 안정화 운동으로 교각운동(bridge exercise) 프 로그램을 적용하였다. <Figure 5>에서 보는 바와 같이 연구대상자에게 교각운동 시 중심 안정성 훈련과 동일 한 자세를 시작자세로 취하도록 하였으며, 무릎은 어 깨 넓이로 벌리고 발의 위치는 어깨와 무릎의 연장선 상에 일직선으로 평행하게 놓고 고정하도록 하였다. 교각운동 시 하지근육의 보상적 움직임이 일어나지 않 도록 하기 위해 무릎과 발의 간격이 최대한 유지되도 록 하였고, 머리와 눈의 방향은 운동 자세에 영향을 미치지 않도록 천장을 향하도록 고정하게 하였다 (Kang et al., 2011). 1 Set에서 1회 당 30초 운동 후, 근피로를 방지하기 위해 30 초의 휴식시간을 설정하였 
으며, 10 회 운동 후에는 3 분의 휴식시간을 설정하였다.

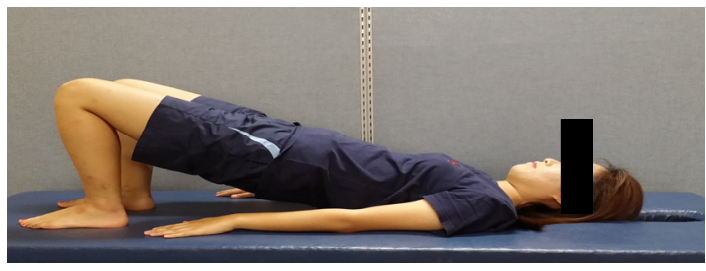

Figure 5. Static stability exercise

\section{동적 안정화 운동}

동적 안정화 운동은 <Figure 6>에서 보는 바와 같 이 space balance 3D 프로그램을 적용하였다. 운동의 강도는 5 단계로 전·후, 좌·우 방향으로 $30^{\circ}$, 총 $60^{\circ}$ 의 범위를 정하였으며, 운동방법은 8자운동으로 가로, 세 로로 지정하여 실시하였다. 본 운동은 가로, 세로 1회 당 2 분씩 총 3 Sets를 시행하였고, 근피로를 방지하기 위해 3분의 휴식시간을 설정하였다(Kim et al., 2009).

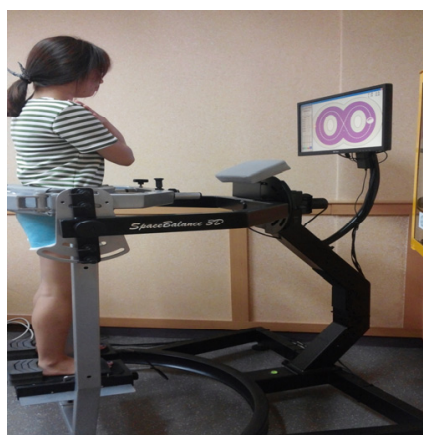

Figure 6. Dynamic stability exercise

\section{자료처리방법}

자료처리는 SPSS/window(version 19.1)을 이용하 측정항목별 평균(M)과 표준편차(SD)를 산출하여 도표 화하였다. 연구대상자의 신체적 특성은 기술통계를 실 시하였다. 기간에 따른 그룹 간 평균치를 검증하기 위 하여 이요인 반복측정분산분석(two-way ANOVA by repeated measurement)을 실시하였다. 유의수준은 $a$ $=.05$ 로 하였다.

\section{연구결과}

\section{체간 근력의 변화}

복부근 근력의 변화는 <Table 2>에서 보는 바와 같이 정적 허리 안정화 운동과 동적 허리 안정화 운 동은 상호작용 효과가 나타났다( $p<.05)$. 사후검증 결과 단기간 허리 안정화 운동프로그램 전후에서 통계학적 으로 유의한 차이가 있었지만( $p<.05)$, 그룹 간에는 통 계적으로 유의한 차이는 없었다.

Table 2. Changes of abdominal muscle strength $(\mathrm{M} \pm \mathrm{SD})$

\begin{tabular}{cccccc}
\hline \multirow{2}{*}{ Group } & \multirow{2}{*}{ Pre } & \multirow{2}{*}{ Post } & \multicolumn{3}{c}{$p$} \\
\cline { 4 - 6 } & & & Time & Group & $\mathrm{T} \times \mathrm{G}$ \\
\hline Static & & & & & \\
stability & $19.25 \pm 8.64$ & $27.06 \pm 4.85$ & & & \\
exercise & & & $.000^{*}$ & .727 & $.005^{*}$ \\
$\begin{array}{c}\text { Dynamic } \\
\text { stability } \\
\text { exercise }\end{array}$ & $15.52 \pm 10.79$ & $28.64 \pm 9.94$ & & & \\
${ }^{*} p<.05$ & & & & & \\
\hline
\end{tabular}

배부근 근력의 변화는 <Table 3>에서 보는 바와 같이 단기간 정적 허리 안정화 운동과 동적 허리 안 정화 운동은 상호작용 효과가 나타났다( $p<.05)$. 사후검 증 결과 단기간 허리 안정화 운동프로그램 전후에서 통계학적으로 유의한 차이가 있었지만 $(p<.05)$, 그룹 간 에는 통계적으로 유의한 차이는 없었다.

Table 3. Changes of back muscle strength $(\mathrm{M} \pm \mathrm{SD})$

\begin{tabular}{cccccc}
\hline \multirow{2}{*}{ Group } & \multirow{2}{*}{ Pre } & \multirow{2}{*}{ Post } & \multicolumn{3}{c}{$p$} \\
\cline { 4 - 6 } & & & Time & Group & $\mathrm{T} \times \mathrm{G}$ \\
\hline \hline $\begin{array}{c}\text { Static } \\
\text { stability } \\
\text { exercise }\end{array}$ & $29.4 \pm 18.53$ & $37.97 \pm 16.62$ & & & \\
$\begin{array}{l}\text { Dynamic } \\
\text { stability } \\
\text { exercise }\end{array}$ & $25.97 \pm 19.04$ & $44.74 \pm 24.99$ & & & \\
${ }^{*} p<.05$ & & & & & \\
\end{tabular}

\section{체간 근지구력의 변화}

복부근 근지구력의 변화는 <Table 4 >에서 보는 바 와 같이 단기간 정적 허리 안정화 운동과 동적 허리 
안정화 운동은 상호작용 효과가 나타나지 않았다 ( $p>05)$. 단기간 허리 안정화 운동프로그램 전후에서 통계학적으로 유의한 차이가 있었지만 $(p<.05)$, 그룹 간 에는 통계적으로 유의한 차이는 없었다.

Table 4. Changes of abdominal muscle endurance( $M \pm S D)$

\begin{tabular}{|c|c|c|c|c|c|}
\hline \multirow{2}{*}{ Group } & \multirow{2}{*}{ Pre } & \multirow{2}{*}{ Post } & \multicolumn{3}{|c|}{$p$} \\
\hline & & & Time & Group & $\mathrm{T} \times \mathrm{G}$ \\
\hline $\begin{array}{c}\text { Static } \\
\text { stability } \\
\text { exercise }\end{array}$ & $34.45 \pm 27.40$ & $67.57 \pm 26.69$ & & & \\
\hline $\begin{array}{l}\text { Dynamic } \\
\text { stability } \\
\text { exercise }\end{array}$ & $45.95 \pm 26.09$ & $73.4 \pm 22.25$ & $.000^{*}$ & .324 & .586 \\
\hline
\end{tabular}

배부근 근지구력의 변화는 <Table 5>에서 보는 바 와 같이 단기간 정적 허리 안정화 운동과 동적 허리 안정화 운동은 상호작용 효과가 나타나지 않았다 ( $p>05)$. 단기간 허리 안정화 운동프로그램 전후에서 통계학적으로 유의한 차이가 있었지만 $(p<.05)$, 그룹 간 에는 통계적으로 유의한 차이는 없었다.

Table 5. Changes of back muscle endurance $(\mathrm{M} \pm \mathrm{SD})$

\begin{tabular}{cccccc}
\hline \multirow{2}{*}{ Group } & \multirow{2}{*}{ Pre } & \multirow{2}{*}{ Post } & \multicolumn{3}{c}{$p$} \\
\cline { 4 - 6 } & & & Time & Group & $T \times G$ \\
\hline \hline $\begin{array}{c}\text { Static } \\
\text { stability } \\
\text { exercise }\end{array}$ & $34.92 \pm 20.60$ & $67.57 \pm 23.45$ & & & \\
$\begin{array}{c}\text { Dynamic } \\
\text { stability } \\
\text { exercise }\end{array}$ & $30.6 \pm 15.99$ & $58.32 \pm 16.74$ & & & \\
${ }^{*} p<.05$ & & & & & \\
\end{tabular}

\section{논의}

허리와 관련된 손상은 서구화된 산업사회에서 점차 적으로 증가하고 있으며(Indahl et al, 1995), 허리통증 을 경험하는 사람은 생활환경에 따라 다르지만 그 범 위는 대략 60 80\%정도이다(Long et al, 1996). 이에, 허리의 불안정 및 만성허리통증을 개선하기 위한 다 양한 접근방법이 시도되고 있으나 비수술적인 방법으 로 운동의 중요성이 대두되고 있다(Ko, 2010).
본 연구에서는 동적 허리 안정화 운동과 정적 허리 안정화 운동을 단기간 적용하여, 어떤 운동이 근력증 가에 더 효과적인지를 알아보고자 하였다.

선행 연구 중 일반 여대생을 대상으로 8주간 허리 안정화 운동을 처치한 결과 운동군은 근지구력이 증 가한 반면 대조군은 약간의 감소를 보여 통계학적으 로 측정시기, 상호작용에서는 유의한 차이가 나타났으 나 그룹 간에는 유의한 차이가 나타나지 않은 사례도 있다(Ko, 2010).

선행연구에서 일반인을 대상으로 4 주간 3 차원 허리 안정화 운동으로 최대 토크, 총 일량, 평균 파워가 각 각 $23 \%, 27 \%, 32 \%$ 로 각각 증가함을 보여 이는 척추 기립근의 근력이 향상되었음을 의미한다고 하였고 (Shin et al., 2012), 또한 퇴행성 변성 디스크 여성 환 자를 대상으로 8 주간 3 차원 운동 강도별로 허리 안정 화 운동을 실시한 결과 중강도와 저강도 두 집단 모 두에서 운동 전에 비해 운동 후에 모든 각도에서 근 력이 유의하게 증가된 것으로 나타났다(Kim et al., 2007). 4 주간 3 차원 동적 운동기기를 이용해 운동한 결과 체간 안정성 및 자세균형에 향상되었다고 하였 다(Shin et al., 2012).

본 연구에서는 복부 및 배부근 근력이 단기간 허리 안정화 운동프로그램 처치 전후에서 유의한 차이가 나타났고( $p<.05)$, 두 그룹 모두 복부 및 배부근 근력을 유의하게 증가하였다. 그룹 간에는 통계적으로 유의한 차이는 없었다. 정적, 동적 안정화 운동 모두 체간 근 력 향상을 통한 허리 안정화를 기대 할 수 있으며, 특 히 만성 허리 통증 질환자의 체간 근력 향상을 위해 space balance $3 \mathrm{D}$ 같은 동적 안정화 운동이 조금 더 도움될 것으로 생각한다.

본 연구에서는 복부근 및 배부근 근지구력이 단기 간 허리 안정화 운동프로그램 처치 전후에서 유의한 차이가 나타났고 $(p<.05)$, 단기간 두 가지 운동 모두 체 간 근지구력을 유의하게 증가시키는 것으로 나타났으 며, 그룹 간에는 통계적으로 유의한 차이는 없었다. 이러한 결과는 단기간 정적 및 동적 허리 안정화 운 동프로그램으로 체간 근지구력 향상을 통한 허리 안 정화를 어느 정도 꾀 할 수 있음을 의미하며 체간 근 력과는 다르게 그룹 간에 단기간 허리 안정화 운동프 로그램 처치 전후 증가 폭에 거의 차이가 없어 체간 
근지구력 향상에 어느 운동 프로그램이 더 효과적이 라고 단정하기 어렵다.

결과적으로 본 연구에서 두 그룹 모두에서 단기간 허리 안정화 운동프로그램 처치 전후 체간 근력 및 근지구력이 유의하게 증가하여 단기간 정적 및 동적 허리 안정화 운동은 만성 허리 통증 환자의 중재 수 단으로 이용가능 할 것으로 생각된다. 그러나, 단기간 정적 안정화 운동 그룹의 배근 근력 및 근지구력의 운동프로그램 처치 전·후 향상정도가 단기간 동적 운동프로그램에 비하여 낮기 때문에 좀 더 장기간의 정적 허리 안정화 운동프로그램 적용이 요구된다고 추론 할 수 있다. 즉, 단기간 정적 허리 안정화 운동 과 동적 허리 안정화 운동 중 어느 운동이 더 효과적 인지를 알아본 결과, 단기간 동적 허리 안정화 운동이 체간 근력에는 더 긍정적인 영향을 미치는 것으로 나 타났지만, 체간 근지구력에서는 동적 안정화 운동과 정적 안정화 운동 간에 차이가 거의 없는 것으로 나 타났다. 아울러, 일상생활에서 단기간 동적 허리 안정 화 운동이 일반인에게 체간 근력을 좋게 해주는 기준 점이 되기도 하지만, 단기간 정적 허리 안정화 운동도 허리 안정화에 도움이 된다는 결과가 도출된 것으로 보아, 단기간 동적 허리 안정화 운동을 할 수 없는 상 황이라면 단기간 정적 허리 안정화 운동도 허리 안정 화에 도움이 된다고 생각된다.

\section{결론 및 제언}

두 그룹 모두에서 단기간 허리 안정화 운동프로그 램 처치 전후 체간 근력 및 근지구력이 유의하게 증 가하여 단기간 정적 및 동적 허리 안정화 운동은 만 성 허리 통증 질환자의 중재 수단으로 이용가능 할 것으로 생각된다. 특히 만성 허리 통증 질환자의 체간 근력 향상을 위해 space balance 3D 같은 동적 안정 화 운동이 조금 더 도움될 것으로 생각한다. 체간 근 지구력에서는 단기간 동적 안정화 운동과 정적 안정 화 운동 중에 두 운동의 효과성에는 차이는 없는 것 으로 나타났다.

결론적으로 단기간 동적 안정화 운동이 정적 안정
화 운동보다 근력 향상에 도움이 된다고 생각한다. 하 지만, 단기간 동적 안정화 운동과 정적 안정화 운동 모두 근지구력에서는 효과성에서 차이가 없음을 알게 되었다. 본 연구결과가 체간 근력과 근지구력을 더 좋 게 하고자 하는 운동선수나 허리통증 환자들의 운동 프로그램 작성 시 기초자료로 활용되기를 기대하며, 향후 연구에서는 운동기간과 연구대상자를 좀 더 다 양하게 적용한다면 더 의미 있는 결과를 얻을 수 있 을 것이라고 생각된다.

\section{참고문헌}

Deeb, J. M., Drury C. G., \& Penderqast D. R. (1992). An exponential model of isometric muscular fatigue as a function of age and muscle groups, Ergonomics, 35(8): 899-918).

Indahl, A., velund, L., \& Reikeraas, O. (1995). Good prognosis for low back pain when left untampered. Spine, 20(4): 437-477.

Jensen M. P., Chen C., \& Bruqqer A. M. (2003). Interpretation of visual analog scale ratings and change scores: a reanalysis of two clinical trials of postoperative pain. The Journal of pain, 4(7): 407-414.

Kang, K. Y., Kwon, H. M, \& Kwon, O. S. (2011). Effect of falls prevention on lumbar stabilization exercise in elderly people. The journal of Korean acaderny of physical therapy science, 18(3): 25-32.

Kim, C. G., B, Y. J., Lee, S. Y., Sung, B. J., \& Choi, S. B. (1999). The Effects of the low back stretching exercise and isotocise on improvement of lumbar strength in chronic low pain patients. The Journal of Exercise Science, 8(3): 383-392.

Kim, G. C. (1999). Back pain management strategy for primary care physician. Korean Journal of Family Medicine, 20(5): 634-646.

Kim, H. D., Lee, K G, \& Lee, J. S. (2009). The effects of fatigue induced by short period of strenuous 
exercise on change of postural static and dynamic postural stability and recovery time. Journal of Sport and Leisure Studies, 38(2): 907-916.

Kim, J. H., Lee, W. H., \& Lee, J. K. (2008). Effects of multifidus muscle volume in patient of lumbar pain according to lumbar exercise methods. The Journal of the Korean Society of Sports Science, 7(2): 1003-1014.

Kim, S. H., Kim, S. S., \& Kim, M. G. (2007). The effects of 3D lumbar stabilization exercise with Exercise intensity on lumbar muscle strength and visual analogue scale of the degenerative disc disease patients. Journal of Sport and Leisure Studies, 31: 933-942.

Ko, Y. H. (2010). Effects of lumbar stabilTraining in fitness and isokinetic muscle function on 8 weeks[master dissertation]. Gachon University at Seongnam.

Kong, Y. S. (2014). The effects of acvivity, thickness and proprioception of trunk muscles according to the methods of bridge exercise in patients with chronic low back pain[doctoral dissertation]. Catholic University at Daegu.

Kwon, W. A. (2006). The effects on 3-dimensional exercise of lumbar stabilization for chronic low Back pain. The journal of Korean academy of physical therapy science, 18(5): 25-34.

Lee, J. S., So Y. S., Kim M. J., Moon S. J., Jang S. D., \& Kim Y. J.,(2011). Effects of the lumbar stabilization exercise on scoliosis, local muscle area, VAS and muscle function in female university students. Exercise Science, 20(1): 62-70.

Lee, S. C. (2009). The influence of unstability of supporting surface on trunk and lower extremity muscle activities during bridging exercise combined with core-stabilization exercise[master dissertation]. Hanseo University at Seosan.

Long, D., BenDebba, M., \& Torgenson, W. (1996). Persistent back pain and sciatica in the united states: patient characteristics. Journal of Spinal Disorders, 9(1): 40-58.

Moreland J, Finch E, Stratord, P., Balsor, B., \& Gill, C. (1997). Interrater reliability of six tests of trunk muscle function and endurance, J Orthop Sports Phys Ther 26: 200-208.

Park, J. H. (2002). Study on strength and rate o the flexor-extensor of knee and hip jiont of the high schoolboys who have low back pain[master dissertation]. Kookmin University at Seoul.

Shin, S. H., You, M, Jeong, K. Y., You, C. H., Kim, K, Jeong, H. C., \& Kwan, D. K. (2012). Effect on the balance ability after four week training using the system for 3-D dynamic exercise equipment, The Journal of Rehabilitative and Assistive Engineering 6(2): 1-8.

Stevens, V. K., BoucheK, K. G., Magieu N. N., Coorevies, P. L., Vanderstraeten, G. G., \& Danneels, L. A. (2006). Trunk muscle activity in healthy subjects during bridging stabilization exercises. BMC Musculoskelet Disord, 20(7): 75

Wang, X. D., \& Wang, H. J. (2009). Establishment of individual exercise therapy model for low back pain. 2009 Second International Symposium on Knowledge Acquisition and Modeling, 1: 122-125.

Wheeler, A. H. (1995). Diagnosis and management of low back pain and sciatica. American Family Physician, 52(5): 133-134. 